\title{
Gt-Thullabb
}

\section{PENGARUH PROGRAM SEHARI BERBAHASA JAWA TERHADAP KETERAMPILAN BERBICARA BAHASA JAWA KRAMA SISWA MI AL JABBAR SUMBERAGUNG DANDER BOJONEGORO}

\author{
Zumrotus Sa'diyah $^{1}$, Siti Nur Laili Febriyanti ${ }^{2}$ \\ ${ }^{1}$ IAI Sunan Giri Bojonegoro, ${ }^{2}$ IAI Sunan Giri Bojonegoro \\ e-mail: ${ }^{1}$ zumrotus.sadiyah@ gmail.com, ${ }^{2}$ lailifebriyanti6@mail.com.
}

\begin{abstract}
Javanese language is the language most widely used by Indonesian people after Indonesian, because the Javanese population is very large, spread throughout Indonesia. But along with the development of the Java language, especially Javanese language krama almost extinct caused by the younger generation lacking appreciation of the Javanese language as their regional language. In this study, researchers will analyze a Javanese language learning program that is a day of Javanese language conducted by MI Al Jabbar with a focus on implementation, manners of language skills, and the effect of the program on students' karmic speaking skills. The results of this study indicate that the Javanese language program runs very well with an average score of 81.4 students. While the effect of a day program in Javanese language with students' language skills occupying the value of the linear regression equation was obtained $Y=25.4+1.331 X$ with the regression significance test showing $F * F$ and by testing the correlation coefficient of $r=0.438$ obtained $t=2.497$ which stated the influence positive between the two variables. And with a significance level of 0.05 obtained $t$ (0.05) (33) <t arithmetic. It can be concluded that there is an influence of a sebaja program (a day in Javanese language) on the skills of speaking Javanese Krama in Al-Jabbar MI Sumberagung Dander Bojonegoro.
\end{abstract}

Kaywords: a day program in Javanese language, speaking skill in Krama

\section{A. Pendahuluan}

Negara Indonesia merupakan negara kepulauan yang memiliki banyak suku bangsa, menurut hasil sensus BPS tahun 2010 indonesia memiliki 1.340 suku bangsa dan memiliki 735 bahasa, jumlah ini menjadikan Indonesia negara nomer dua yang mempunyai banyak Bahasa. kurang lebih terdapat data yang disampaikan SIL (Summer Institute of Linguistic) menunjukan adanya 735 bahasa daerah di Indonesia. Dari 735 bahasa daerah tersebut 83 dinyatakan sehat karena penuturnya 100.000 atau lebih. Sisanya, 637 dalam kondisi mengkhawatirkan, 12 tidak diketahui, dan 3 dinyatakan punah. Sedangkan menurut jumlah penuturnya Bahasa terbanyak di gunakan di Indonesia ialah : 1) Bahasa jawa 2) Bahasa melayu-indonesia, 3) Bahasa sunda, 4) 
Bahasa Madura 5) Bahasa Batak, 6) Bahasa Minangkabau 7) Bahasa Bugis 8) Bahasa Aceh 9) Bahasa Bali 10) Bahasa Bancar.

Bahasa merupakan alat komunikasi dalam kehidupan sehari-hari dilihat dari urutan penuturan terbanyak Bahasa jawa menduduki urutan pertama. Dwi Bambang Putut Setiyadi menyatakan bahwa bahasa Jawa merupakan bahasa yang mengenal adanya tingkat tutur (speech levels) atau undha-usuk atau unggahungguhing basa. Bahasa juga dapat dijadikan sebagai alat pemersatu bagi pemilik bahasa itu. Misalnya bahasa Jawa yang merupakan bahasa daerah masyarakat Jawa merupakan alat pemersatu bagi seluruh orang Jawa, baik yang terdapat di Jawa, maupun orang Jawa yang berada di luar daerahnya atau berada di perantauan. Oleh karena pentingnya keberadaan bahasa daerah itulah, perlu diadakan usaha-usaha untuk melestarikan bahasa daerah yang akhir-akhir ini mulai tersisihkan. Salah satunya dengan adanya hari wajib Sehari berbahasa Jawa untuk mempertahankan bahasa Jawa agar tidak punah, bahasa Jawa krama Khususnya. Hari wajib berbahasa Jawa krama adalah penetapan hari tertentu semua kegiatan dan komunikasi harus menggunakan bahasa pengantar bahasa Jawa krama.

Berdasarkan peraturan Menteri Pendidikan Nasional RI Nomor 22 dan 23 tahun 2006, mengenai kurikulum Kurikulum Tingkat Satuan Pendidikan (KTSP) yang merupakan penyempurnaan dari KBK (Kurikulum Berbasis Kompetensi). Amanat yang terkandung dalam KTSP adalah bahwa peserta didik akan mendapatkan bekal berbagai kompetensi sesuai dengan perubahan dan perkembangan serta aspirasi terhadap gejalagejala yang muncul di masyarakat. Terkait dengan hal itu maka ditetapkanlah bahasa, sastra dan budaya Jawa sebagai muatan lokal wajib dijenjang pendidikan SD/MI, SMP/MTs, SMA/SMK/MA. Penentuan kebijakan tersebut didasari oleh fungsi bahasa. Sebagaimana diketahui bahwa fungsi utama bahasa Jawa adalah sebagai sarana komunikasi dalam masyarakat Jawa, maka pembelajaran bahasa, sastra dan budaya Jawa bertujuan agar siswa terampil berkomunikasi menggunakan bahasa Jawa (Mulyana, 2008). Pendidikan merupakan kunci terpenting dan tolak ukur dari keberhasilan suatu bangsa untuk dapat bersaing didalam dunia internasional. Undangundang No 20 tahun 2003 Tentang Sistem pendidikan Nasional, dijelaskan bahwa yang dimaksud dengan pendidikan adalah usaha sadar dan terencana untuk mewujudkan suasana belajar dan proses pembelajaran agar peserta didik secara aktif mengembangkan potensi dirinya untuk memiliki kekuatan spiritual keagamaan, pengendalian diri, kepribadian, kecerdasan, akhlaq mulia, serta keterampilan yang diperlukan untuk dirinya dan masyrakat (Indonesia, 2003).

Putut Setiyadi menyatakan bahwa banyaknya bahasa daerah yang hampir punah disebabkan karena siswa atau generasi muda kurang menghargai bahasa ibu sebagai bahasa daerahnya. Tak terkecuali bahasa Jawa krama yang saat ini juga mulai 
tersisihkan. Beberapa orang beranggapan bahwa pemakaian bahasa Jawa krama sebagai alat komunikasi dalam kehidupan sehari-hari sebagai penanda ketidakmajuan atau ketinggalan jaman, sehingga intensitas penggunaan bahasa Jawa semakin berkurang dan intensitas penggunaan bahasa Indonesia dan bahasa internasional semakin meningkat. Belakangan ini bahasa Jawa krama sudah mengalami kemunduran secara fungsional, hal ini disebabkan oleh terus menyempitnya pemahaman terhadap jagat kata bahasa Jawa (Setyawan, 2019).

Dalam hal ini penerapan Bahasa jawa masuk dalam dunia pendikan melalui berbagai kegiatan, program pembelajaran dan kurikulum seperti kegiatan sehari berbahasa jawa, muatan local Bahasa jawa, ekstra kulikuler Bahasa jawa dan lain-lain. Seperti halnya di MI al jabbar sumberagung dander bojonegoro sekolah melaksanakan program sehari berbahasa jawa yang sudah berjalan satu tahun. Berdasarkan hasil observasi dan wawancara dengan beberapa sumber di lapangan didapatkan informasi bahwa pelaksanaan program Sebaja (Sehari Berbahasa Jawa) yang baru diterapkan sekitar satu tahun terakhir ini hanya diterapkan setiap hari Sabtu. Jadi program tersebut tidak hanya untuk siswa tetapi juga semua warga lingkungan sekolah. Pengaruh dan manfaat dirasakan oleh siswa maupun warga lingkungan sekolah dengan adanya program tersebut.

Pada pelaksanaan hari wajib Sehari berbahasa Jawa, siswa diwajibkan menggunakan bahasa Jawa krama pada semua kegiatan yang dilakukannya dan saat berkomunikasi dengan siapapun. Hal ini berarti menuntut siswa untuk memiliki kemampuan berbahasa Jawa krama dan kemampuan itu salah satunya dapat diperoleh siswa pada mata pelajaran bahasa Jawa dan program sehari berbahasa jawa. Siswa juga membutuhkan motivasi belajar saat mengikuti pelajaran bahasa Jawa. Jika siswa mampu mencapai hasil belajar bahasa Jawa yang baik tentu hal ini akan menunjang pelaksanaan hari wajib berbahasa Jawa. Demikian juga pelaksanaan hari wajib Sehari berbahasa Jawa akan menunjang pembelajaran bahasa Jawa. ${ }^{1}$

Berdasarkan uraian diatas, jika seorang siswa dibiasakan menggunakan bahasa jawa krama sehari-hari, akan lancar dan mudah memahami konsep bahasa dirumah maupun sekolah. Pemahaman konsep yang benar akan membantu siswa dalam memperoleh hasil belajar yang maksimal.

\section{B. Metode}

1 Sutarni Neni Sugianti, Hubungan Intensitas Penggunaan Bahasa Jawa pada Hari Wajib Berbahasa Jawa Dengan Motivasi Belajar Bahasa Jawa Siswa Sekolah Dasar Negeri Keputran 1 (Yogyakarta: UIN,2013) hlm. 06 
Penelitian yang digunakan adalah penelitian eksperimen. Penelitian eksperimen diartikan sebagai jenis penelitian kuantitatif yang paling penuh, artinya memenuhi syarat untuk menguji hubungan sebab akibat (Sugiyono, 2015). Penelitian eksperimen merupakan bentuk penelitian percobaan yang berusaha untuk mengisolasi dan melakukan kontrol setiap kondisi-kondisi yang relevan dengan situasi yang diteliti kemudian melakukan pengamatan terhadap efek atau pengaruh ketika kondisi-kondisi tersebut dimanipulasi. Dengan kata lain perubahan atau manipulasi dilakukan terhadap variabel bebas dan pengaruhnya diamati pada variabel terikat.

Metode eksperimen disebut juga sebagai metode percobaann metode eksperimen menurut tujuannya terdiri dari 3 bentuk eksperimen pembuktian, eksperimen penemuan, dan eksperimen perencanaan tindakan. Meskipun sama-sama menggunakan metode percobaan, ketiga bentuk metode penelitian eksperimen berbeda versi dan aplikasi (Muliawan, 2014).

Dalam hal ini peneliti sengaja membangkitkan timbulnya suatu kejadian atau keadaan kemudian diteliti bagaimana akibatnya. Dengan kata lain eksperimen adalah suatu cara untuk mencari hubungan sebab akibat (kausal) antara dua faktor yang sengaja di timbulkan oleh peneliti dengan mengeliminasi atau menyisikan faktor-faktor lain yang bisa mengganggu (Suharsimi Arikunto, 2006). Sehingga dengan penelitian eksperimen dapat mengetahui ada atau tidaknya pengaruh program Sebaja (Sehari berbahasa Jawa) terhadap keterampilan berbicara bahasa Jawa krama.

Peneliti menentukan populasi dari penelitian ini adalah seluruh siswa MI Al Jabbar, sedangkan sampel penelitian kelas 4,5, dan 6 yang berjumlah 36. Teknik pengumpulan data dalam penelitian ini ialah observasi, wawancara, dokumentasi, angket dan tes. Sedangkan analisis data menggunakan regresi linier yang dilakukan dua tahap, pertama tahap menentukan persamaan regresi dengan rumus sebagai berikut:

$=\mathrm{a}+\mathrm{b} X$

Yang dapat dicari dengan rumus:

$\mathrm{a}=\frac{(\Sigma Y)\left(\sum X^{2}\right)-(\Sigma X)(\Sigma X Y)}{n \sum X^{2}-(\Sigma X)^{2}}$

$\mathrm{b}=\frac{n\left(\sum X Y\right)-\left(\sum X\right)\left(\sum Y\right)}{n \sum X^{2}-\left(\sum X\right)^{2}}$

keterangan:

$\mathrm{X}=$ variabel bebas

$\mathrm{Y}=$ variabel terikat

a = bilangan konstan (intercept garis regresi)

b =koenfisien pre dictor (slore garis regresi) (Sumanto, 2005) 
Kemudian tahap kedua, uji kelinieran dan keberartian regresi dilakukan dengan pengujian hipotesis bahwa regresi tidak linier (Ho) melawan hipotesis bahwa regresi linier (Ha). Sedangkan keberartian regresi diperiksa melalui pengujian hipotesis bahwa koefisien-koefisien refresi sama dengan nol (tidak berarti) melawan hipotesis tandingan bahwa koefisien arah regresi tidak sama dengan nol (berarti) (Sudjana, 2006). Uji kelinieran dapat dilakukan dengan terlebih dahulu menghitung jumlah kuadrat-kuadrat (Jk) antara lain:

1) Menghitung jumlah kuadrat total (Jk) (T)

$$
\mathrm{Jk}(\mathrm{T})=\sum Y^{2}
$$

2) Menghitung jumlah kuadrat koefisien (a)

$$
\mathrm{Jk}(\mathrm{a})=\frac{\left(\sum Y\right)^{2}}{n}
$$

3) Menghitung jumlah kuadrat regresi (b) terhadap (a)

$$
\mathrm{Jk}(\mathrm{b} / \mathrm{a})=\mathrm{b}\left\{\sum X Y-\frac{(\Sigma X)(\Sigma Y)}{n}\right\}
$$

4) Menghitung jumlah kuadrat sisa

$$
\mathrm{Jk}(\mathrm{s})=\sum Y^{2} J k(a)-J k(\mathrm{~b} / \mathrm{a})
$$

3) Menghitung jumlah kuadrat galat

$$
\mathrm{Jk}(\mathrm{G})=\sum\left\{\sum Y^{2}-\frac{(\Sigma Y)^{2}}{n}\right\}
$$

4) Menghitung jumlah kuadrat tuna cocok

$$
\mathrm{Jk}(\mathrm{TC})=\mathrm{Jk}(\mathrm{s})-\mathrm{Jk}(\mathrm{G})
$$

5) Menghitung derajat kebebasan (dk)

6) Menghitung kuadrat tengah (KT)

7) Menghitung nilai (F) untuk menguji hipotesis nol bentuk regresi linier melawan non linier

$$
\mathrm{F}=\frac{s^{2} \text { reg }}{s^{2} \text { sis }}
$$

8) Menghitung nilai $\mathrm{F}$ untuk menguji hipotesis nol koefisien arah regresi tidak berarti melawan koefisien berarti 


$$
\mathrm{F}=\frac{s^{2} T C}{s^{2} G}
$$

\section{Hasil dan Pembahasan}

Berdasarkan analisis statistik diatas, maka peneliti uraikan hasil perhitungan tersebut sebagai berikut:

1. Menentukan persamaan regresi

Berdasarkan hasil perhitungan regresi linier sederhana diatas diperoleh persamaan sebagai berikut:

$\mathrm{Y}=25,4+1,331 \mathrm{X}$

Dari persamaan diatas dapat diinterprestasikan sebagai berikut:

$\mathrm{a}=25,4$ berarti perpotongan garis regresipada sumbu (Y) terletak pada 25,4 nilai ini tergantung pada nilai variabel bebas $(\mathrm{X})$

$\mathrm{b}=1,331$ berarti bahwa apabila program sebaja (sehari berbahasa Jawa) apabila ditingkatkan keefektifannya sebesar satu satuan, maka akan diikuti kenaikan keterampilan berbicara siswa sebesar 1,331 dengan asumsi bahwa variabel lainnya konstan.

2. Uji lineritas

Berdasarkan pada perhitungan uji lineritas diatas dapat diketahui bahwa $\mathrm{F}$ hasil penelitian $\left(\mathrm{F}^{*}\right)=0,018<$ dari $\mathrm{F}$ tabel baik pada taraf nyata $0,05=2,901$. Berarti bahwa Ha model regresi linier yang menyatakan adanya hubungan yang linier diterima.

Dengan diterimanya hipotesis model regresi linier menunjukkan adanya pengaruh atau hubungan program sebaja (sehari berbahasa Jawa) terhadap keterampilan berbicara bahasa Jawa krama siswa.

3. Uji koefisien korelasi

Berdasarkan hasil pengolahan diatas diperoleh harga koefisien korelasi (r) sebesar 0,438, kemudian untuk menguji signifikasi hasil korelasi digunakan uji t dengan taraf signifikasi $5 \%$ dan $\mathrm{dk}=33$ diperoleh nilai $\mathrm{t}(0,05)(33)$ sebesar 2,03 sedangkan t hitung sebesar 2,497 menyatakan ada hubungan positif atau hubungan searah antara kedua variabel dalam arti jika variabel $\mathrm{X}$ (program sebaja (sehari berbahasa Jawa)) naik, maka variabel Y (keterampilan berbicara bahasa Jawa krama) juga naik. Maka dapat disimpulkan bahwa t $(0,05)(33)<\mathrm{t}$ hitung sehingga hipotesis nol ditolak. Jadi ada pengaruh program sebaja (sehari berbahasa Jawa) terhadap keterampilan berbicara bahasa Jawa krama sebesar 43,8\% dengan asumsi bahwa variabel lainnya konstan. 


\section{Simpulan}

Setelah dilakukan penelitian, maka dapat diambil kesimpulan sebagai berikut:

1. Secara keseluruhan penerapan program sehari berbahasa Jawa telah menunjukkan pada kategori sangat baik, terbukti pada nilai tes bahasa Jawa krama yang telah dikerjakan siswa yaitu dengan rata rata nilai 81,4.

2. Hasil penelitian menunjukkan adanya keterampilan berbicara bahasa jawa krama setelah diterapkannya program sebaja (sehari berbahasa Jawa). Dari persamaan regresi linier diperoleh $\mathrm{Y}=25,4+1,331 \mathrm{X}$ dengan uji keberartian regresi menunjukkan $\mathrm{F}^{*}>\mathrm{F}$ dan dengan pengujian koefisien korelasi dari $\mathrm{r}=0,438$ diperoleh $\mathrm{t}=2,497$ yang menyatakan adanya pengaruh positif antara kedua variabel. Dan dengan taraf nyata 0,05 diperoleh $\mathrm{t}(0,05)(33)<\mathrm{t}$ hitung. Dapat disimpulkan bahwa ada pengaruh program sehari berbahasa Jawa terhadap keterampilan berbicara bahasa Jawa krama di MI Al-Jabbar Sumberagung Dander Bojonegoro. Dan berdasarkan perhitungan $\mathrm{r}$ determinan diketahui besarnya pengaruh penerapan program sebaja sehari berbahasa Jawa terhadap keterampilan berbicara bahasa Jawa krama sebesar 43,8\% dengan asumsi bahwa variabel lainnya konstan.

\section{SARAN}

Sebagaimana hasil penelitian yang telah dipaparkan, peneliti menyarakan agar peneliti yang akan datang mengembangkan penelitianya pada berbagai kegiatan pengembangan Bahasa jawa yang lainya, agar kegiatan Bahasa jawa lebih maju.

1. Kepada para guru, agar program sebaja (sehari berbahasa Jawa) ini dikembangkan dengan sebaik-baiknya guna meningkatkan keterampilan berbicara bahasa Jawa krama yang lebih baik.

2. Dengan hasil penelitian ini, hendaknya dapat menggugah minat para pembaca atau mahasiswa lain untuk terus melanjutkan penelitian ini dengan desain yang berbeda dan lebih baik.

\section{Daftar Rujukan}

Indonesia, R. Undang-Undang No. 20 Tahun 2003 tentang Sistem Pendidikan Nasional. Warga Negara. Masyarakat. Pemerintah. Pemerintah Daerah. Lembaran Negara Republik Indonesia, Pub. L. No. 4301 (2003).

Muliawan, J. U. (2014). Metodelogi Penelitian Pendidikan dengan Studi Kasus. Yogyakarta: Gava Media.

Mulyana. (2008). Pembelajaran Bahasa dan Sastra Daerah Dalam Kerangka Budaya. Yogjakarta: Tiara Wacana.

Setyawan, I. (2019). "Sikap Generasi "Z” terhadap bahasa Jawa: Studi kasus pada anak-anak usia Sekolah Dasar di kota Semarang”. Semarang: Universitas Diponegoro.

Sudjana. (2006). Teknik Analisis Regresi dan Korelasi Bagi Peneliti. Bandung: Tarsito. 
Zumrotus Sa'diyah, Siti Nur Laili Febriyanti

Sugiyono. (2015). Metode Penelitian Pendidikan (Pendekatan Kuantitatif, Kualitatif, dan $R \& D)$,. Bandung: Alfabeta.

Suharsimi Arikunto. (2006). Prosedur Penelitian: Suatu Pendekatan Praktik. Jakarta: Rineka Cipta.

Sumanto. (2005). Metodologi Penelitian Sosial dan Pendidikan. Yogyakarta: Andi Offset. 